Results: A German cohort of 150 AxSpA patients with 89 male and 61 female patients (mean age 49.3 years for males, 48.5 for females, $p=0.77$ ) was analyzed for functional capacity. Female patients had a significantly higher functional impairment in everyday life compared to males $(p=0.013)$. After adjusting for age, linear regression showed female sex still to be significantly associated with functional impairment. Female patients rated their satisfaction with health as well as their physical and mental health-related quality of life significantly lower than male patients $(p=0.015$, respectively $p=0.003$ and $p=0.002)$.

There were no significant differences in disease duration, diagnostic delay or family history between male and female patients $(p=0.731, p=0.971$ and $p=0.776$ ). Women had a slightly higher disease activity (BASDAI 4.08 vs. 3.36 ), although just not statistically significant in our cohort $(p=0.056)$. Female patients had more peripheral joint involvement $(52.5 \%$ vs. $34.8 \%, p=0.032)$, as well as more enthesitis $(31.1 \%$ vs. $16.9 \%, p=0.04)$, whereas there were no differences concerning eye involvement $(p=0.51)$. Female patients were less likely to be HLA B27 positive ( 65.6 vs. $80.7 \%, p=0.04$ ). and were less likely to be on anti-TNF treatment $(p=0.032$, respectively $p=0.042)$.

Conclusion: Also in our cohort female patients had a higher burden of disease as well as a worse patient reported outcome with worse quality of life and more self-reported functional impairment in everyday life. These data underline the importance of raising awareness for sex differences in disease presentation and suggest that female patients might require different treatment to achieve improved outcomes.

Disclosure of Interests: None declared

DOI: 10.1136/annrheumdis-2020-eular.5895

\section{AB0683 \\ IS THE NEW ASDAS NOMENCLATURE IN LINE WITH THERAPEUTIC DECISION MAKING IN PATIENTS WITH AXIAL SPONDYLOARTHRITIS?}

B. Garcia-Magallon ${ }^{1}$, M. D. C. Castro Villegas ${ }^{2}$, R. Rosselló ${ }^{1}$, V. Navarro-Compán ${ }^{3}$ ${ }^{1}$ Hospital San Jorge Huesca, Huesca, Spain; ${ }^{2}$ University Hospital Reina Sofía Córdoba, Córdoba, Spain; ${ }^{3}$ University Hospital La Paz Madrid, IdiPaz, Madrid, Spain

Background: The Assessment of SpondyloArthritis international Society (ASAS) proposed in 2018 a change in the nomenclature of the Ankylosing Spondylitis Disease Activity Score (ASDAS) for monitoring disease activity in axial spondyloarthritis (axSpA), renaming the previously status of moderate disease activity as low disease activity status, with the presumption that this better reflects the perception that the doctor and the patient have about the disease situation. However, this decision was not data-driven.

Objectives: To evaluate the association between the state of low disease activity according to the new ASDAS nomenclature and the therapeutic decision in patients with axSpA.

Methods: Longitudinal retrospective study in which patients with axSpA recruited in a secondary hospital were included. All patients with clinical diagnosis of axSpA who started treatment with a first inhibitor of tumor necrosis factor between January 2014 and June 2019 were included. At each follow-up visit, disease activity assessments (including BASDAI and CRP) and the therapeutic decision of the doctor were collected. Later, the ASDAS was calculated and disease status at each visit was classified according to the new nomenclature (inactive, low, high and very high activity). Using descriptive statistics, the association between the disease activity status and the therapeutic decision was evaluated.

Results: A total of 304 visits were analyzed in 104 patients with axSpA. Out of these, $57 \%$ were women, $47 \%$ had a subtype of non-radiographic axSpA and $42 \%$ were HLA-B27 positive. The mean (standard deviation) age at diagnosis was 46.9 (12.5) years. In the visits with an ASDAS showing a status of low activity, the therapeutic attitude was not to intensify the treatment in $98.2 \%$ of the cases. However, in visits with an ASDAS status of high or very high disease activity, treatment was intensified in $33.7 \%$ and $82.8 \%$ of cases, respectively.

Conclusion: In clinical practice, the status of disease activity initially classified by the ASDAS as moderate disease activity is currently considered to represent low disease activity status based on the therapeutic attitude of following a non-intensification strategy in this situation. These data support the recent change in the nomenclature of disease activity states according to the ASDAS.

References:

[1] Machado PM, Landewé R, van der Heijde D. Assessment of Spondyloarthritis international Society (ASAS). Ankylosing Spondylitis Disease Activity Score (ASDAS): 2018 update of the nomenclature for disease activity states. Ann Rheum Dis 2018; 77:1539-1540.

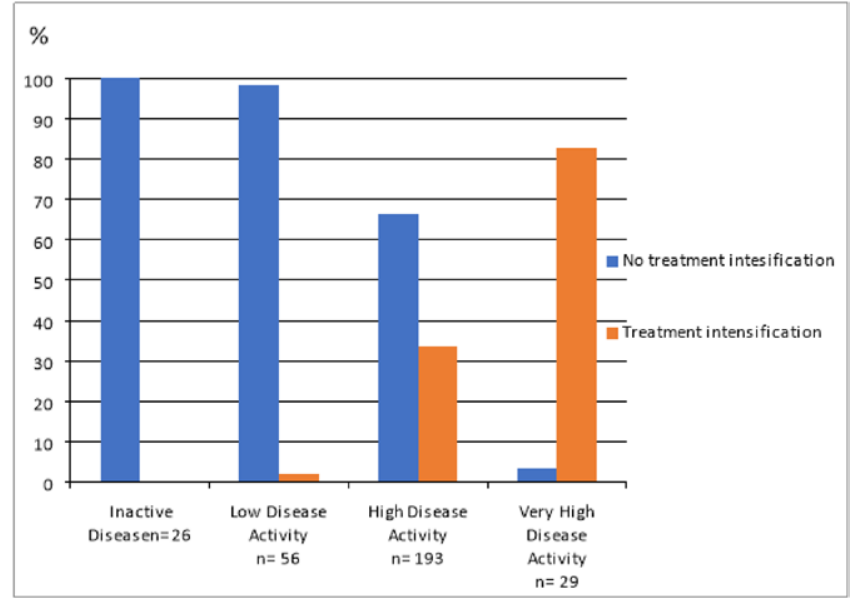

Figure 1. Association between the state of disease activity according to the new ASDAS nomenclature and the therapeutic decision.

Disclosure of Interests: Blanca Garcia-Magallon Consultant of: MSD, Speakers bureau: Pfizer, Amgen, Celgene, MSD, María del Carmen Castro Villegas: None declared, Rosa Rosselló: None declared, Victoria Navarro-Compán Consultant of: Abbvie, Lilly, Novartis, Pfizer, UCB, Speakers bureau: AbbVie, MSD, Lilly, Novartis, Pfizer, UCB

DOI: 10.1136/annrheumdis-2020-eular.2224

\section{AB0684 COMPARATIVE ANALYSIS OF PATIENT-REPORTED OUTCOMES AMONG EMPLOYED AND UNEMPLOYED PATIENTS WITH AXIAL SPONDYLOARTHRITIS. RESULTS OF THE SPANISH ATLAS 2017}

M. Garrido-Cumbrera ${ }^{1,2}$, J. Gratacos-Masmitja ${ }^{3,4}$, E. Collantes-Estévez ${ }^{5,6}$, P. Zarco Montejo ${ }^{7}$, C. Sastré ${ }^{8}$, J. Correa-Fernández ${ }^{1}$, P. PlazueloRamos $^{2}$, V. Navarro-Compán ${ }^{9}$ on behalf of Atlas Working Group. ${ }^{1} \mathrm{Health}$ \& Territory Research, Universidad de Sevilla, Seville, Spain; ${ }^{2}$ Spanish Federation of Spondyloarthritis Associations (CEADE), Madrid, Spain; ${ }^{3}$ Hospital Universitari Parc Taulí, Sabadel, Spain; ${ }^{4}$ ISPT, UAB, Barcelona, Spain; ${ }^{5}$ Reina Sofia University Hospital, Cordoba, Spain; ${ }^{6}$ Maimonides Biomedical Research Institute of Cordoba (IMIBIC), University of Cordoba, Cordoba, Spain; ${ }^{7}$ Hospital Fundación Alarcón, Madrid, Spain;

${ }^{8}$ Novartis Spain, Barcelona, Spain; ${ }^{9}$ IdiPAZ, University Hospital La Paz, Madrid, Spain

Background: Unemployment is associated with poorer disease outcomes in chronic conditions. Current high rates of unemployment in Spain may lead to a higher burden of disease in axial spondyloarthritis (axSpA) patients.

Objectives: To evaluate the differences in sociodemographic factors and patient-reported outcomes (PROs) between employed and unemployed axSpA patients in the same sample.

Methods: Data from 680 unselected patients of the Spanish Atlas of Axial Spondyloarthritis from an online survey were collected in 2016 were analysed. Active workforce participants were divided into employed and unemployed according to International Labour Organization (ILO) standards. Socio-demographic characteristics, and Patient-reported Outcomes (PROs) [BASDAI (0-10), spinal stiffness (3-12), functional limitation (0-54) and psychological distress (0-12, General Health Questionnaire GHQ-12)] were compared between employed and unemployed participants. The $\mathrm{X}^{2}$ test was used for qualitative variables and the Mann-Whitney test for quantitative variables.

Results: In total, $415(63.6 \%)$ patients were categorised in the active population, of which $325(78.3 \%)$ were employed and $90(21.6 \%)$ unemployed (Table 1). $62.8 \%(\mathrm{~N}=86)$ of unemployed patients declared that axSpA was the cause of their joblessness. Compared to the unemployed, the employed patients had a higher percentage of university studies $(47.1 \%$ vs $23.3 \%$; $p=0.001)$ and higher income level per family member ( $€ 890.4$ vs $€ 358.5 ; p<0.001$ ). In relation to PROs, the unemployed presented greater disease activity $(6.3 \pm 1.9$ vs $5.2 \pm 1.9$; $p<0.001)$ and spinal stiffness $(7.8 \pm 2.3$ vs $6.5 \pm 2.6)$, worst functional limitation $(45.0 \pm 8.4$ vs $40.6 \pm 10.1 ; p<0.001)$ and more psychological distress $(7.6 \pm 4.2$ vs $4.9 \pm 4.3 ; p<0.001)$. In addition, a higher proportion of unemployed participants self-reported anxiety $(27.8 \%$ vs $16.0 \%$; $p=0.011)$ and depression $(23.3 \%$ vs 10.2\%; $p=0.001$ ) (Table 2). 
Table 1. Employment status of Spanish Atlas survey respondents

\begin{tabular}{|c|c|c|c|c|c|}
\hline Population & $\mathbf{N}$ & $\%$ & Employment status & $\mathbf{N}$ & $\%$ \\
\hline \multirow[t]{3}{*}{ Active population* } & 415 & 63.6 & Employed & 325 & 78.3 \\
\hline & & & Unemployed & 90 & 21.6 \\
\hline & & & Total & 415 & 100.0 \\
\hline \multirow[t]{7}{*}{ Inactive population } & 238 & 36.4 & Temporary sick leave & 63 & 26.5 \\
\hline & & & Permanent sick leave & 64 & 26.9 \\
\hline & & & Retired & 63 & 26.5 \\
\hline & & & Homemakers & 29 & 12.2 \\
\hline & & & Students & 9 & 3.8 \\
\hline & & & Early retirement & 10 & 4.2 \\
\hline & & & Total & 238 & 100.0 \\
\hline Total & 653 & 100.0 & & & \\
\hline
\end{tabular}

${ }^{*}$ According to the ILO

Table 2. Association between sociodemographic characteristics and PROs comparing employed and unemployed axSpA patients

\begin{tabular}{|c|c|c|c|}
\hline & $\begin{array}{c}\text { Employed } \\
(\mathrm{N}=325) \\
\text { Mean } \pm \mathrm{SD} \text { or } \mathrm{n}(\%)\end{array}$ & $\begin{array}{c}\text { Unemployed } \\
(\mathrm{N}=90) \\
\text { Mean } \pm \mathrm{SD} \text { or } \mathrm{n}(\%)\end{array}$ & p-value \\
\hline \multicolumn{4}{|l|}{ Sociodemographic } \\
\hline Age (years) & $42.9 \pm 8.6$ & $42.0 \pm 9.1$ & 0.513 \\
\hline Gender (Male) & $159(48.9)$ & $36(40.0)$ & 0.133 \\
\hline Education level (University) & $153(47.1)$ & $21(23.3)$ & $0.001^{*}$ \\
\hline Marital status (Married) & $231(71.1)$ & $54(60.0)$ & 0.051 \\
\hline Monthly Income $(€)$ & $890.4 \pm 592.3$ & $358.5 \pm 377.7$ & $<0.001^{*}$ \\
\hline \multicolumn{4}{|l|}{ PROs } \\
\hline Diagnostic Delay (years) & $7.7 \pm 7.6$ & $8.0 \pm 6.5$ & 0.319 \\
\hline BASDAI $(0-10)$ & $5.2 \pm 1.9$ & $6.3 \pm 1.9$ & $<0.001^{*}$ \\
\hline Spinal Stiffness (3-12) & $6.5 \pm 2.6$ & $7.8 \pm 2.3$ & $<0.001^{*}$ \\
\hline Global Limitation Index (0-54) & $40.6 \pm 10.1$ & $45.0 \pm 8.4$ & $<0.001^{*}$ \\
\hline GHQ-12 (0-12) & $4.9 \pm 4.3$ & $7.6 \pm 4.2$ & $<0.001^{*}$ \\
\hline Anxiety & $52(16.0)$ & $25(27.8)$ & $0.011^{\star}$ \\
\hline Depression & $33(10.2)$ & $21(23.3)$ & $0.001^{*}$ \\
\hline Sleep disorder & $50(15.4)$ & $18(20.0)$ & 0.295 \\
\hline
\end{tabular}

Conclusion: The Spanish Atlas results show significant differences between employed and unemployed patients with axSpA, with greater disease activity, spinal stiffness, functional limitation, and poorer mental health in those who are unemployed.

Acknowledgments: Funded by Novartis Pharma AG \& Novartis Farmacéutica S.A.

Disclosure of Interests: Marco Garrido-Cumbrera: None declared, Jordi Gratacos-Masmitja Grant/research support from: a grant from Pfizzer to study implementation of multidisciplinary units to manage PSA in SPAIN, Consultant of: Pfizzer, MSD, ABBVIE, Janssen, Amgen, BMS, Novartis, Lilly, Speakers bureau: Pfizzer, MSD, ABBVIE, Janssen, Amgen, BMS, Novartis, Lilly, Eduardo Collantes-Estévez Grant/research support from: ROCHE and Pfizer., Speakers bureau: ROCHE, Lilly, Bristol and Celgene., Pedro Zarco Montejo Grant/research support from: Pfizzer, MSD, ABBVIE, Janssen, Amgen, BMS, Novartis, Lilly, Speakers bureau: Pfizzer, MSD, ABBVIE, Janssen, Amgen, BMS, Novartis, Lilly, Carlos Sastré Employee of: YES; I'm Medical Advisor in Novartis Spain, José Correa-Fernández: None declared, Pedro Plazuelo-Ramos: None declared, Victoria Navarro-Compán Consultant of: Abbvie, Lilly, Novartis, Pfizer, UCB, Speakers bureau: AbbVie, MSD, Lilly, Novartis, Pfizer, UCB DOI: 10.1136/annrheumdis-2020-eular.5728

\section{AB0685 IMPACT OF AXSPA ON WORKING LIFE: RESULTS FROM 233 PATIENTS OF THE RUSSIAN FEDERATION PARTICIPATING IN THE EUROPEAN MAP OF AXIAL SPONDYLOARTHIRTIS (EMAS)}

1. Gaydukova ${ }^{1}$, M. Garrido-Cumbrera ${ }^{2}$, T. Dubinina ${ }^{3}$, A. Dubikov ${ }^{4}$,

E. Zonova ${ }^{5}$, M. Korolev ${ }^{6}$, S. Lapshina ${ }^{7}$, P. Pchelnikova ${ }^{8}$, I. Shipilova ${ }^{9}$,

A. Sitalo ${ }^{10} .{ }^{1}$ North-Western State Medical University n.a. II Mechnikov, St. Petersburg, Russian Federation; ${ }^{2}$ Universidad de Sevilla, Health and Territory Research (HTR), Seville, Spain; ${ }^{3}$ VA Nasonova Research Institute of Rheumatology, Moscow, Russian Federation; ${ }^{4}$ Clinic of rheumatology, Vladivostok, Russian Federation; ${ }^{5}$ Research Institute of Clinical and Experimental Lymphology, Novosibirsk, Russian Federation; ${ }^{6}$ Novosibirsk State Medical University, Novosibirsk, Russian Federation; ${ }^{7}$ Kazan State Medical University, Kazan, Russian Federation; ${ }^{8}$ All-Russian Patient Union, Moscow, Russian Federation; ${ }^{9}$ Novartis Pharma LLC, Moscow, Russian Federation; ${ }^{10}$ Russian Ankylosing Spondylitis Association, Moscow, Russian Federation
Background: Axial spondyloarthritis (axSpA) has been shown to impact patients' (pts) professional opportunities, employment status and work productivity [1]. Objectives: To evaluate employment status, work-related issues and their interrelation with the disease-related characteristics among Russian axSpA pts.

Methods: The European Map of Axial Spondyloarthritis (EMAS) was a cross-sectional on-line survey of pts with self-reported axSpA conducted in 13 European countries. Russian participants were recruited between Dec 2017 and Feb 2018 through the Russian Ankylosing Spondylitis Association and an online panel. Socio-demographic, BASDAl, psychological distress (GHQ-12), working status and work-related issues (e.g. taking sick leave, difficulties fulfilling or reducing working hours, etc.) were assessed.

Results: 233 Russian pts participated in EMAS. The mean age was $36.7 \pm 9.1$ years, $51.9 \%$ were female, and the mean disease duration was $12.4 \pm 9.5$ years Of the 233,226 reported their employment status and productivity, of which $73.45 \%$ were employed, $12.39 \%$ were unemployed, $4.42 \%$ were on sick leave, $3.54 \%$ were homemakers, $2.21 \%$ were retired, $2.21 \%$ were on early retirements, $1.77 \%$ were students. Of the 160 pts, who reported their occupation, $73(45.63 \%)$ were employed and had jobs requiring higher education qualifications, $39(24.38 \%)$ had management positions, $23(14.38 \%)$ were skilled manual workers and $12(7.50 \%)$ were skilled non-manual workers, $3(1.88 \%)$ were occupied in armed forces, $3(1.88 \%)$ pts worked as unskilled workers. 124 (76.54\%) of 162 pts survey respondents declared to have suffered work issues related to their disease in the 12 months prior to the survey. The most common work-related issue was difficulty fulfilling working hours in 69 (56.56\%), followed by taking sick leave $49(40.16 \%)$ and asking for days off $44(36.07 \%)$ out of 122 pts. Pts who reported any type of issues at work had higher BASDA and psychological distress (GHQ-12 score) (table 1). 145 (76.32\%) out of 190 responded pts reported that their choice of workplace had been influenced by the disease $(68.25 \%)$.

Table 1. BASDAI and GHQ-12 by work-related issues and difficulty fulfilling working hours due to axSpA.

\begin{tabular}{lccccccc}
\hline Any type of issue at work & BASDAI & \multicolumn{7}{c}{ GHQ-12 } \\
\hline & Mean & SD & N & Mean & SD & N \\
\hline No & $3.14^{\star}$ & 1.93 & 38 & $2.95^{\star}$ & 3.39 & 38 \\
Yes & $4.97^{\star}$ & 2.08 & 124 & $6.53^{\star}$ & 3.76 & 124 \\
Difficulty fulfilling working hours & Mean & SD & N & Mean & SD & N \\
No & $4.53^{\star *}$ & 2.15 & 55 & $5.49^{\star \star}$ & 3.80 & 55 \\
Yes & $5.32^{\star \star}$ & 1.96 & 69 & $7.36^{\star *}$ & 3.54 & 69 \\
\hline
\end{tabular}

* Mann-Whitney test $p$-values $<0.001$

** Mann-Whitney test $p$-values $<0.05$

Conclusion: Results from the Russian sample of the EMAS survey highlight the impact of axSpA in working life. Patients with any type of work-related issue mark above the cut-off point of BASDAI and GHQ-12, so work-related issues are associated to a status of high disease activity and a risk of poor mental health. Among all work-related issues surveyed, the presence of presenteeism (measured by difficulty fulfilling working hours) is associated to both a clinical and significant increase in disease activity through BASDAI.

References:

[1] van Lunteren, M., et al. https://doi.org/10.1093/rheumatology/kex365.

Disclosure of Interests: Inna Gaydukova Grant/research support from: JSC BIOCAD, Speakers bureau: Pfizer, Novartis, AbbVie, JSC BIOCAD, Celgene, MSD, Sanofi, Marco Garrido-Cumbrera: None declared, Tatiana Dubinina Speakers bureau: Novartis, BIOCAD, MSD, Pfaizer, Abbvie, UCB, Alexander Dubikov: None declared, Elena Zonova Speakers bureau: Pfizer, Abbvie, Bayer, Janssen, Lilly, Maxim Korolev: None declared, Svetlana Lapshina: None declared, Polina Pchelnikova: None declared, Irina Shipilova Employee of: Novartis Pharma LLC, Alexey Sitalo: None declared

DOI: 10.1136/annrheumdis-2020-eular.4875

\section{AB0686 ONLINE QUESTIONNAIRE CAN IMPROVE DELAY IN AXIAL SPONDYLOARTHRITIS DIAGNOSTICS. RESULTS OF SAINT PETERSBURG AXSPA EARLY DIAGNOSTICS PROJECT}

E. Gaydukova ${ }^{1}$, V. Mazurov ${ }^{1,2}$, O. Inamova ${ }^{1,2}$, E. Vasilenko ${ }^{1,2}$, I. Gaydukova $^{1,2}$. ${ }^{1}$ Clinical Rheumatological Hospital №25, St. Petersburg, Russian Federation; ${ }^{2}$ North-Western State Medical University named after I. I. Mechnikov, St. Petersburg, Russian Federation

Background: Due to current data mean diagnostics delay in axial spondyloarthritis $(\mathrm{axSpA})$ is $7.4 \pm 8.4$ years (mean $\pm \mathrm{SD}$ ) [1]. However, development 